\title{
IMPROVED MELATONIN CONTENT AND ANTIOXIDANT ACTIVITY OF MUNG BEAN SPROUT BY GERMINATION UNDER SALINITY INCORPORATED WITH EXOGENOUS MELATONIN
}

\author{
ANUCHITA MOONGNGARM*, ARISA CHAIYARAK, KANYAPUK PRACHANUN AND \\ SUPAP NONTASAN
}

Research Unit of Nutrition for Life, Department of Food Technology and Nutrition, Faculty of Technology, Mahasarakham University, Maha Sarakham 44150, Thailand.

*Corresponding author: anuchitac@yahoo.co.th

Submitted final draft: 25 August $2020 \quad$ Accepted: 11 September $2020 \quad$ http://doi.org/10.46754/jssm.2021.02.009

\begin{abstract}
Melatonin is a natural hormone produced by the pineal gland in the brain to regulate human circadian rhythms. It is often used to treat sleep disorders, and as an antioxidant. High melatonin and antioxidant mung bean sprouts were produced. The effects of germination time, sodium chloride $(\mathrm{NaCl})$ stress, exogenous melatonin treatment on the improvement of endogenous melatonin, total phenolic compounds (TPC) and antioxidant profiles of mung bean sprouts were evaluated using the response surface method (RSM). Eleven conditions of germination were generated using a fractional factorial design. The results indicated that all conditions led to a germination rate of over $92 \%$. An increase in germination time, $\mathrm{NaCl}$ concentration, and exogenous melatonin resulted in the elevation of endogenous melatonin, TPC and antioxidant activity of sprouts. Optimal conditions for the germination of mung bean sprouts were $0.50 \% \mathrm{NaCl}, 30 \mu \mathrm{M}$ melatonin, with a germination time of $72 \mathrm{~h}$. The experimental values under these conditions were 942.88 $\mathrm{ng} / \mathrm{g}$ for melatonin, $1.83 \mathrm{mg} / \mathrm{g}$ for total phenolic content, $0.95 \mathrm{mg}$ Trolox equivalent (TE)/g, for DPPH radical scavenging assay, and $11.02 \mathrm{mg} \mathrm{TE} / \mathrm{g}$, for total antioxidant capacity. Germination under these conditions is considered a potential process that could be adopted to produce ready-to-eat sprouts, or functional ingredients with high concentration of melatonin for the food industry.
\end{abstract}

Keywords: Melatonin, Antioxidant activity, Mung bean, Germination, Phenolic compounds.

\section{Introduction}

The popularity of functional food products has recently increased as consumers become more aware of their benefits. Various raw materials can be developed into functional food to meet rising customer demand. Melatonin is an interesting bioactive compound that is used to control the circadian rhythms of the human body, and as an antioxidant. Melatonin is a neuroendocrine hormone produced in the pineal gland during the daily dark period. It is synthesized primarily by the tryptophan metabolic pathway, with serotonin being the precursor in the pineal gland (Murch et al., 2000). The roles of melatonin in humans include sleep-promoting activities (Zhdanova, 2005), increasing sleep propensity and the synchronizing effect of the body circadian rhythms (Cardinali et al., 2002). Melatonin administration is useful for ameliorating jet-lag symptoms (Arendt, 1995; Arendt, 1997; Cardinali et al., 2002). Moreover, several studies indicated that melatonin exhibits an immunomodulatory potential (Maestroni et al., 2001; Guerrero and Reiter, 2002; CarrilloVico et al., 2005; Pandi-Perumal et al., 2006). Melatonin has also been extensively reported as a potent antioxidant, both in vitro (Tan et al., 2003) and in vivo (Reiter et al., 2005; Piechota et al., 2010; Sae-Teaw et al., 2013). Recently, a role of melatonin in neurodegenerative diseases treatment (such as Alzheimer's and Parkinson's diseases) has been suggested. Many reports demonstrated that melatonin treatments improved sleep, amelioratde sun-downing, and slowed the evolution of cognitive impairment 
in Alzheimer's patients (Srinivasan et al., 2005; Wu \& Swaab, 2005).

Currently, most commercially available melatonin is obtained from chemical synthesis. Therefore, extraction of melatonin from natural food materials would offer an interesting potential alternative. Several studies have investigated the amount of melatonin in plants, including fruits, seeds, grains, seeds, nuts and herbs (Zhang et al., 2015; Martín-Cabrejas et al., 2017). Legumess are a good source of tryptophan and serotonin; both precursors for melatonin synthesis (Khan et al., 2014; Saleh et al., 2019). The mung bean (Vigna radiata L.) is one of the most important short-season cultivated legumes. The seeds and sprouts are good sources of antioxidants, widely consumed over the world as a vegetable. Germination is a biotechnological process widely applied in legumes as an effective technique to enhance the digestibility and nutritional quality of legume seeds. Recently, the consumption of sprouts from legumes has increased as part of a safe and healthy diet pattern. It has been recognised that the germination process affects the nutrient content and bioactive components, such as increases in protein and mineral contents, decreases in fat content, and the enhancement of antioxidant activity (Dahiya et al., 2013; Huang et al., 2014). The latter may be attributed to increased flavonoid, vitamin $\mathrm{C}$, as well as total and free phenolic content, which occurs during the germination process (Guo et al., 2012; Doblado et al., 2007). In addition, the previous study by Sansopha et al. (2020) indicated that many legumes were good source of melatonin, but there was no information about melatonin in mung bean and the influence of germination on melatonin content. Some studies reported that seed germination in many plants under stressful conditions, such as salinity, produced higher levels of melatonin and antioxidants (Saha et al., 2012; Aguilera et al., 2015). Therefore, here, food materials were produced containing high levels of melatonin and antioxidants for use as a source of melatonin in functional foods. Moreover, mung bean seed germination rate is reduced in salty conditions; therefore, to increase germination rate, melatonin was added since research has indicated that melatonin could reduce plant stress and improve the seed germination rate (Saha et al., 2012; Sehrawat et al., 2014; Aguilera et al., 2015; Liu et al., 2015; Win \& Oo, 2015). This study was conducted to investigate the optimum conditions for germination of mung bean seeds under salinity to obtain high melatonin content and the antioxidant activity of mung bean sprout.

\section{Materials and Methods}

\section{Chemicals and Materials}

Melatonin standard, 2,2-diphenyl-1-picrylhydrazyl radical (DPPH) and Folin-Ciocalteu phenol reagent (FCR), Trolox standard (TE) (6-hydroxy-2,5,7,8-tetramethylchroman-2carboxylic acid) and gallic acid were purchased from Sigma-Aldrich Chemical Co., (St. Louis, MO, USA). Acetonitrile and methanol (grade HPLC), and L-ascorbic acid (vitamin C) were purchased from BDH (Poole, UK). Mung bean (Vigna radiata (L.) Wilczek) was obtained from a supermarket in Maha Sarakham Province, Thailand.

\section{Mung Bean Germination}

The germination of mung bean was performed by following the method of Tang et al. (2014) with some modifications. Mung bean seeds were inspected before soaking in tap water (seeds to water ratio; $1: 4$ ) for approximately $8 \mathrm{~h}$ until a moisture content of $40 \%$ was obtained. Soaked mung bean seeds were then germinated in an automatic bean sprout machine (BSM007-CY, China) at $28 \pm 2^{\circ} \mathrm{C}$ and $80 \%$ relative humidity. The seeds were watered automatically by the machine sprinkler with different concentrations of saline water $(0,0.25$ and $0.5 \% \mathrm{NaCl})$ and melatonin $(0,15$, and $30 \mu \mathrm{M})$. The sprinkled water was changed daily. During germination, the samples were removed from the chamber every 24,48 , and $72 \mathrm{~h}$ for each treatment. After that, the samples were dried using a freezedrying machine (Heto PowerDry PL3000, Czech Republic). The dried samples were blended, then packed in ziplock plastic bags, and stored at 
$-20^{\circ} \mathrm{C}$ until required for further use. This study consisted of three variables at the low level (-1), medium level $(0)$ and high level $(+1)$. The three conditions of sodium chloride level $(\mathrm{NaCl})(\%)$, exogenous melatonin concentration $(\mathrm{Mel})(\mu \mathrm{M})$, and germination time $(\mathrm{h})$ were designated as $\mathrm{X} 1$, $\mathrm{X} 2$, and $\mathrm{X} 3$, respectively.

\section{Physiological Study}

The length of mung bean sprouts was measured using a Vernier caliper and expressed in millimeters (Mendoza-Sánchez et al., 2016). The growth ratio was estimated by counting the germinated seed sprouts and the result was reported as germination rate (number of germinated seeds x 100/total number of seeds) (Mendoza-Sánchez et al., 2016).

\section{Moisture Content (MC) Analysis}

The moisture content was determined according to the standard methods of analysis (AOAC, 2000). A ground sample (5 g) was placed in a moisture can and then dried using a hot air oven at $100 \pm 2^{\circ} \mathrm{C}$. After that, the can with the sample was moved to a desiccator before weighing. The moisture content was calculated as follow:

Moisture content $(\%)=\left(\mathrm{W}_{3}-\mathrm{W}_{1}\right) /\left(\mathrm{W}_{2}-\mathrm{W}_{1}\right) \times 100$

Where $\mathrm{W}_{1}$ = initial weight of moisture can, $\mathrm{W}_{2}$ = weight of moisture can + sample (before drying), and $\mathrm{W}_{3}=$ final weight of moisture can + sample (after drying).

\section{Sample Extraction}

A dried sample $(10 \mathrm{~g})$ was extracted with 50 $\mathrm{mL}$ of $80 \%$ methanol $(\mathrm{MeOH})$ and then shaking incubated for $16-22 \mathrm{~h}$ at $150 \mathrm{rpm}$ at room temperature. The extraction was filtered, and the supernatant was collected for melatonin, phenolic content and antioxidant activity analysis.

\section{Melatonin Determination}

The melatonin content was determined according to the methods of Kocadağlı et al.
(2014) and Pothinuch and Tongchitpakdee (2011). The extracted sample was purified using solid phase extraction (SPE) and activated with $10 \mathrm{ml}$ of $\mathrm{MeOH}$, followed by $10 \mathrm{ml}$ of deionized (DI) water. The extracted sample (5 $\mathrm{ml}$ ) was loaded onto the SPE cartridge and the impurity was washed with $10 \mathrm{ml}$ of $5 \% \mathrm{MeOH}$ and then eluted with $5 \mathrm{ml}$ of $80 \% \mathrm{MeOH}$. The eluted sample was filtrated using a $0.2 \mu \mathrm{m}$ filter before a liquid chromatography-tandem mass spectrometry (LC/MS-MS) analysis was carried out. The mobile phase was prepared as (A) $0.45 \%$ formic acid in DI water and (B) acetonitrile in the ratio $(50: 50, v / v)$. An InertSustain ${ }^{\circledR} \mathrm{C} 18$ column $(2.1 \times 150 \mathrm{~mm}$ i.d., $3 \mu \mathrm{m}$ ) with the column oven set at $40^{\circ} \mathrm{C}$ was used. Isocratic elution was performed with $2 \mu \mathrm{l}$ of injection volume, flow rate at $0.2 \mathrm{~mL} /$ min and total running time of $10 \mathrm{~min}$. Mass spectral data were acquired in the positive mode and identification of melatonin was performed using multiple reaction monitoring (MRM) with electrospray ionization (ESI) settings. Nitrogen gas was used for nebulizing and drying at flow rates of $3 \mathrm{~L} / \mathrm{min}$ and $15 \mathrm{~L} / \mathrm{min}$, respectively, with $4.5 \mathrm{kV}$ interface voltage at $250^{\circ} \mathrm{C}$ and $400^{\circ} \mathrm{C}$ for the desolvation line (DL) and the heat block. The MS (Q3 scan) was selected for product ion scans using argon as the collision induced dissociation (CID) gas at $230 \mathrm{kPa}$. Transition at $233.0 \rightarrow 174.0$ (collision energy of $-15 \mathrm{ev}$ ) was used to detect melatonin with a dwell time at $100 \mathrm{~ms}$.

\section{Total Phenolic Content (TPC) Determination}

The total phenolic content was determined according to the method of (Iqbal et al., 2005). The extracted sample $(0.2 \mathrm{ml})$ was mixed with $0.8 \mathrm{ml}$ of Folin-Ciocalteu reagent at a ratio of $1: 10$ with water. Then, $0.2 \mathrm{ml}$ of sodium carbonate $(7.5 \% \mathrm{w} / \mathrm{v})$ was added and the volume was adjusted up to $7.0 \mathrm{ml}$ with DI water. The mixture was kept in dark conditions at room temperature for $2 \mathrm{~h}$. Absorbance at $765 \mathrm{~nm}$ was measured. The results were expressed as $\mathrm{mg}$ gallic acid equivalents/g sample. 


\section{Free Radical Scavenging Activity (DPPH) Assay}

The stability of free 2,2-diphenyl-1picrylhydrazyl radical scavenging assay (DPPH) was determined following the method of Shimada et al. (1992) with slight modifications. The extracted sample $(2.5 \mathrm{ml})$ was added with $7.5 \mathrm{ml}$ of DPPH radical $(0.1 \mathrm{mmol})$ and the mixture was shaken vigorously using a vortex mixer (Harmony, Japan), left for $30 \mathrm{~min}$ in the dark and then measured at $517 \mathrm{~nm}$ using a Libra S12 UV-vis spectrophotometer (Biochrom, Cambridge, UK). The Trolox standard (TE), vitamin $\mathrm{C}(\mathrm{VC})$ and gallic acid (GAE) were used as standards, with results expressed as mg antioxidant standard equivalents/g sample.

\section{Total Antioxidant Capacity (TAC) Assay}

The reagent solution was prepared by mixing $33.67 \mathrm{ml}$ of sulfuric acid, $4.59 \mathrm{~g}$ of sodium phosphate and $0.784 \mathrm{~g}$ of ammonium molybdate and adjusted with distilled water up to $1,000 \mathrm{ml}$. The extracted sample $(1 \mathrm{ml})$ and $4 \mathrm{ml}$ of reagent solution were added, then mixed and incubated at $95^{\circ} \mathrm{C}$ for $90 \mathrm{~min}$. The reaction was measured at $695 \mathrm{~nm}$. Results were expressed as mg TE, VC and GAE/g sample (Phatak \& Hendre, 2014).

\section{Statistical Analysis}

RSM was adopted to evaluate the effects of germination time, $\mathrm{NaCl}$ stress and exogenous melatonin application on the improvement of endogenous melatonin, as well as total phenolic content (TPC) and antioxidant profiles of mung bean sprouts. Eleven experiments were generated using a fractional factorial design. Three variables included salinity level $(0,0.25$, $0.5 \%)$, exogenous melatonin concentration $(0$, $15,30 \mu \mathrm{M})$ and germination time $(24,48,72 \mathrm{~h})$. Mathematical models were obtained based on the multiple determination coefficients $\left(\mathrm{R}^{2}\right)$ and analysis of variance (ANOVA). The responses were optimized to obtain the optimal condition. Data were analyzed using Design-Expert Software version 7.1.5.

\section{Results and Discussion}

\section{Germination Characteristics of Mung Bean} Seeds

The results of seed germination are presented in Table 1. It was observed that mung bean seeds germinated well under salinity $(0.5 \%$ $\mathrm{NaCl}$ ), with germination rate not significantly different from seeds germinated under normal conditions (over $92 \%$ germination rate) after 24 h. However, germination of mung bean seeds under salinity conditions resulted in a significant decline in total seedling length, with germination time constant at $72 \mathrm{~h}$. The total length of sprouts germinated under $0.5 \% \mathrm{NaCl}$ was significantly shorter $(8.14 \mathrm{~cm})$ than seeds germinated without salt treatment $(19.05$ and $20.63 \mathrm{~cm})$. This indicated that $\mathrm{NaCl}$ treatment at $0.5 \%$ during germination negatively affected mung bean seed germination by reducing seedling growth. The reduction of the total length of sprouts could be the result of suffering from osmotic stress and/ or ion toxicity of $\mathrm{NaCl}$ during seed germination, resulting in suppression of shoot and root growth (Chowdhury et al., 2018). However, exogenous melatonin treatment of seeds at $30 \mu \mathrm{M}$ tended to increase the length of mung bean sprouts. Results concurred with Aguilera et al. (2015), who reported that $20 \mu \mathrm{M}$ of melatonin-enriched watering significantly enhanced the radicle development of lentil and kidney bean sprouts at up to 1.4-1.6 times more than those treated with water due to the auxin-like activity of melatonin, which promotes vegetative development (Arnao and Hernández-Ruiz, 2006).

\section{Endogenous Melatonin Content of Mung Bean Sprouts}

The experimental data for endogenous melatonin in the germination of mung bean sprouts under different combinations of variables are shown in Table 1. The contents of endogenous melatonin obtained from mung bean sprouts varied from 3.59 to $967.21 \mathrm{ng} / \mathrm{g}$ for the different treatments. The results indicated that seed germinated under $0.5 \% \mathrm{NaCl}$ and added with $30 \mu \mathrm{m}$ of melatonin for $72 \mathrm{~h}$ yielded the highest concentration of 
melatonin (967.21 ng/g), while germination without $\mathrm{NaCl}$ and added melatonin had the lowest amount of melatonin $(3.59 \mathrm{ng} / \mathrm{g})$.

Analysis of variance (ANOVA) presented in Table 3 shows that the regression model for melatonin was statistically significant ( $p \leq 0.001)$ with $\mathrm{R}^{2}=0.997$, indicating a good model adjustment to the experimental data. The predicted model for melatonin is described by the equations in Table 3 in terms of coded values. Regression analysis of endogenous melatonin indicated that germination time, $\mathrm{NaCl}$ and exogenous melatonin treatments had a significantly positive effect on endogenous melatonin content in mung bean sprouts at $p \leq 0.01, p \leq 0.001$ and $p \leq 0.001$, respectively. There was also a significant interaction between $\mathrm{NaCl}$ and exogenous melatonin treatment, as well as exogenous melatonin treatment and germination time on the elevation of endogenous melatonin content in mung bean sprouts $(p \leq 0.01)$. The response surface showing the effect of $\mathrm{NaCl}$, melatonin treatments and germination time on endogenous melatonin content in sprouts is

967.213

3.5932

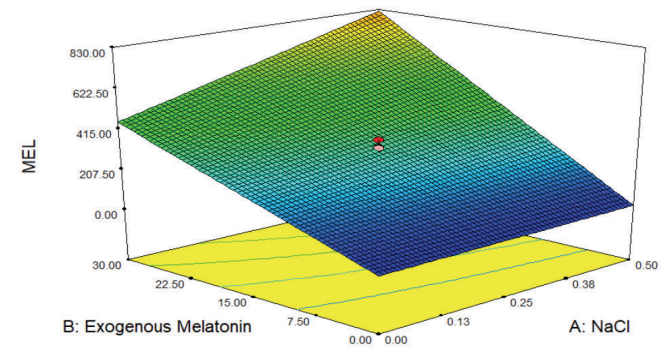

shown in Figure 1. Germination of mung bean seeds under the absence of salt contributed to an increase of endogenous melatonin in sprouts to $3.59 \mathrm{ng} / \mathrm{g}$ and $6.11 \mathrm{ng} / \mathrm{g}$ at 24 and $72 \mathrm{~h}$, compared with $2.56 \mathrm{ng} / \mathrm{g}$ in raw seeds. However, treatment of salt at $0.5 \%$ enhanced accumulation of endogenous melatonin in the sprouts. A similar increase in endogenous melatonin concentration of legume sprouts during a long period of germination time was also reported by Saleh et al. (2019). Elevated levels of melatonin in sprouts under salinity conditions occurred because melatonin is a bioactive functional plant substance involved in the regulation of stress responses in plants (Tan et al., 2012; Parades et al., 2009). Arnao \& Hernandez-Ruiz (2013) reported that using $10 \mathrm{mM}$ of $\mathrm{NaCl}$ as a chemical stressor showed increased endogenous melatonin levels in lupin roots. Exogenous melatonin treatment of mung bean seeds during germination resulted in a considerable increase in endogenous melatonin levels to 360.28 and $572.90 \mathrm{ng} / \mathrm{g}$ at 24 and $72 \mathrm{~h}$, respectively. These results concurred with Aguilera et al. (2015). They found that germination of legume seeds
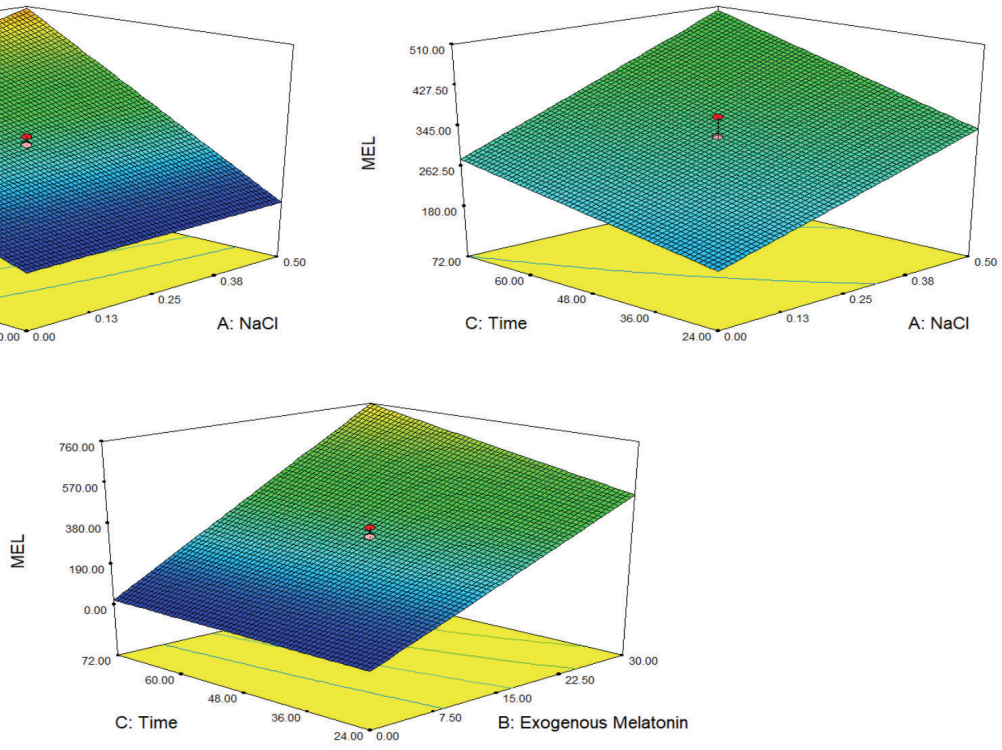

Figure 1: The response surface showing the effect of $\mathrm{NaCl}$, exogenous melatonin treatment and germination time on endogenous melatonin content in mung bean sprouts 
with exogenous melatonin watering enhanced the accumulation of endogenous melatonin concentration in sprouts. Mukherjee et al. (2014) reported that the $\mathrm{NaCl}$ treatment increased the melatonin content in roots and cotyledons of sunflower sprouts.

\section{Total Phenolic Content of Mung Bean Sprouts}

It is well known that biosynthesis of secondary metabolites, including phenolic compounds in seeds, is enhanced during germination (Cáceres et al., 2014; Huang et al., 2014; Pająk et al., 2014). Phenolics are important bioactive compounds that exhibit a broad range of biological functions in plants, such as reduction of oxidative damage resulting from the formation of reactive oxygen species (ROS) during plant development and stress (Waśkiewicz et al., 2012). Germination of seeds with exogenous melatonin and $\mathrm{NaCl}$ treatments has been reported to impact changes of phenolic concentration (Aguilera et al., 2015; Gengmao et al., 2015, Lim et al., 2012). However, the effects of these variables on the total phenolic content and information on optimal conditions to maximize phenolic content in mung bean seeds are rarely reported.

The effects of $\mathrm{NaCl}$ and melatonin treatments during mung bean seed germination on the mean values of TPC content are shown in Table 1. TPC contents in mung bean sprouts germinated under different conditions varied from 0.61 to $1.86 \mathrm{mg} / \mathrm{g}$, higher than in raw seeds $(0.34 \mathrm{mg} / \mathrm{g})$. Analysis of variance (ANOVA) presented in
Table 3 shows that the regression model for TPC content was significant $(p<0.0001)$, and the lack of fit was insignificant. This indicated that the model could explain $98.29 \%$ of all variance in data. The regression coefficients of $\mathrm{NaCl}$ level, exogenous melatonin concentration and germination time were positive $(p \leq 0.01$, $p \leq 0.01$ and $p \leq 0.01$, respectively) as described by the equations in Table 3, with the response surface shown in Figure 2. However, there was no significant interaction between variables on TPC. The results revealed that mung bean seeds germinated under the presence of $0.5 \%$ $\mathrm{NaCl}$ showed an increase in TPC compared with seeds germinated under the absence of salt. The addition of exogenous melatonin during seed germination had a tendency to increase the content of TPC. A long germination period led to a significant increase in TPC in mung bean sprouts. The highest concentration of total phenolics (1.86 mgGAE/g) was investigated in mung bean sprouts germinated under $0.5 \%$ $\mathrm{NaCl}$ with $30 \mu \mathrm{M}$ of exogenous melatonin solution for $72 \mathrm{~h}$. The results indicated that the germination of mung bean seeds led to a dramatic increase in TPC content in sprouts compared with ungerminated mung bean seeds, consistent with the findings by Gan et al. (2016) and Guo et al. (2012). Moreover, germination of seeds under salinity stress and exogenous melatonin treatment induced the accumulation of TPC compared with a previous study on the content of total phenolics in mung bean sprouts after $72 \mathrm{~h}$ of traditional germination (Guo et al., 2012). 


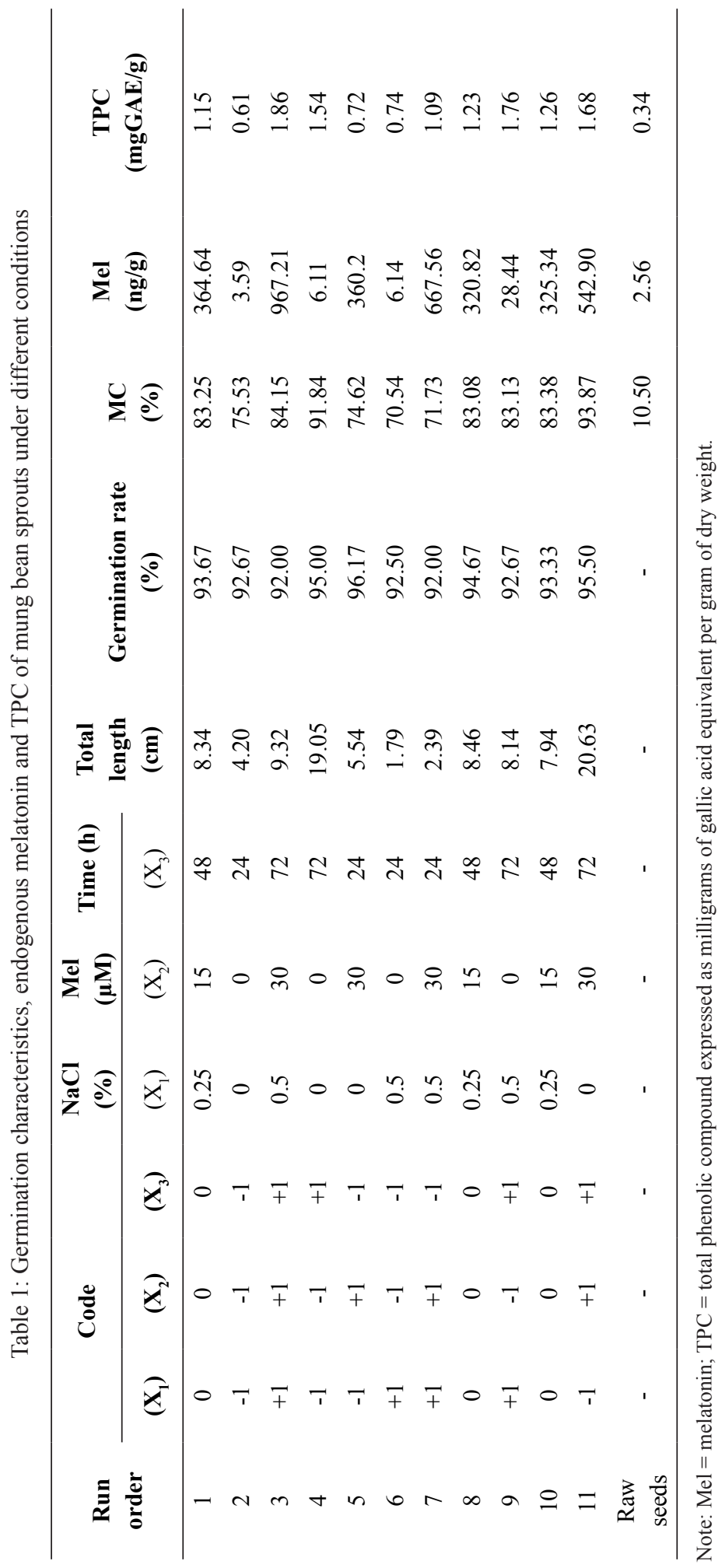



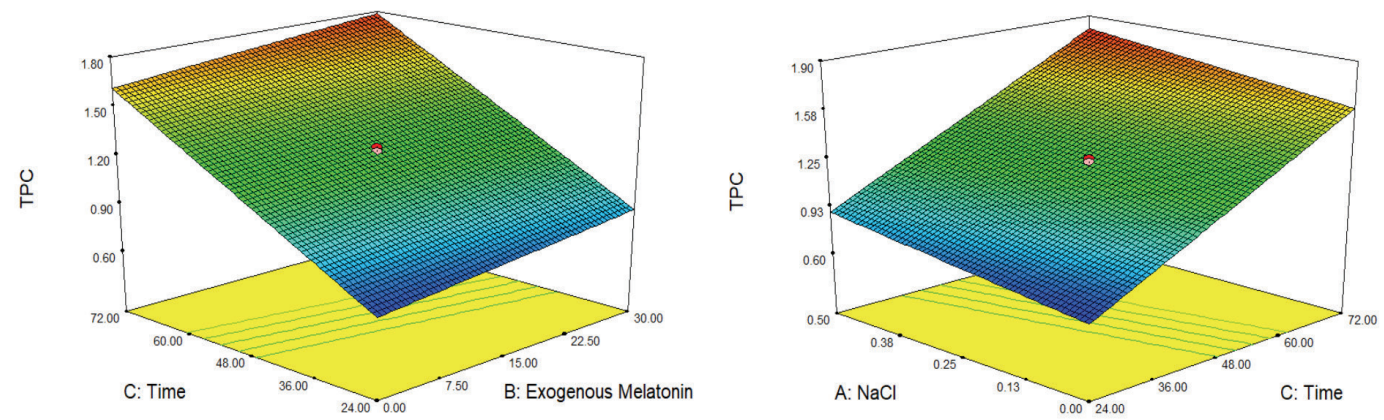

Figure 2: The response surface showing the effects of $\mathrm{NaCl}$, exogenous melatonin treatment and germination time on TPC in mung bean sprouts

\section{Antioxidant Activities of Mung Bean Sprouts}

The antioxidant activities of extracts on DPPH radical and Mo (VI) using Trolox, ascorbic acid, and gallic acid as references were evaluated as shown in Table 2 and Figure 3. The predicted models for antioxidant activities that were statistically significant $(p \leq 0.001)$ and fitted well are presented in Table 3. Similar to the changes in endogenous melatonin and total phenolic content, $\mathrm{NaCl}$ level, exogenous melatonin concentration and germination time significantly stimulated antioxidant activity as determined by the phosphomolybdate assay (total antioxidant capacity) $(p \leq 0.001)$. However, only $\mathrm{NaCl}$ level and germination time significantly affected the antioxidant activity measured by DPPH radical scavenging assay $(p \leq 0.05$ and $p \leq 0.01$, respectively). The increase in antioxidant activity of mung bean seeds during germination has been previously assessed by Guo et al. (2012) and Pająk et al. (2014). The results indicated that $\mathrm{NaCl}$, exogenous melatonin treatments and a long period of germination stimulated antioxidant activities of mung bean sprouts. This could be related to the antioxidative effect of melatonin, TPC accumulated during seed germination and salinity stress. Similar results in improvement of antioxidant status in sprouts caused by high concentration of melatonin were observed in lentils by Aguilera et al. (2015), while $\mathrm{NaCl}$ stress during seed germination induced increase of antioxidant activity (Lim et al., 2012). Under salinity condition, the highest activity determined by the phosphomolybdate assay (total antioxidant capacity) was found in mung bean seeds treated with $0.5 \% \mathrm{NaCl}$ combined with $30 \mu \mathrm{M}$ of melatonin solution for $72 \mathrm{~h}$ (Table 2). 
0.976544

0.667029
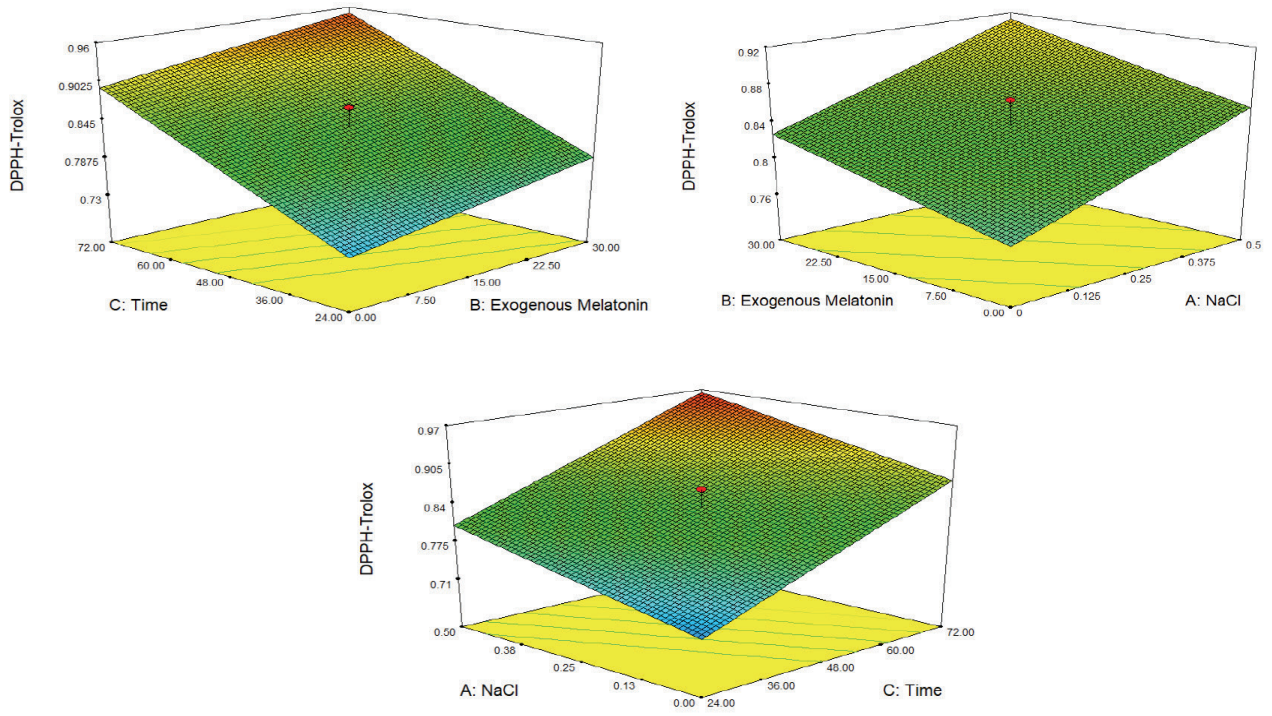

3.75093
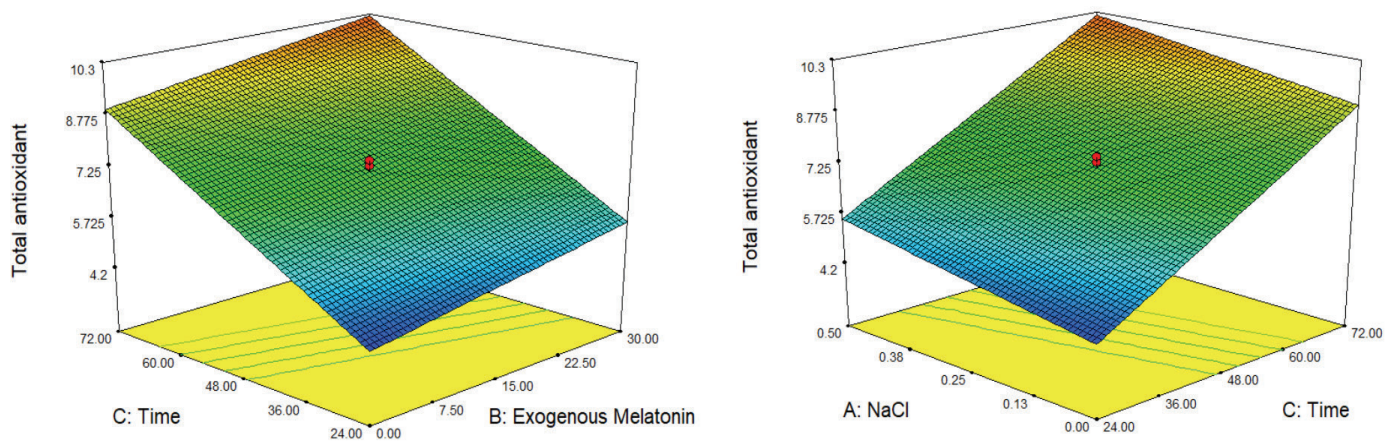

Figure 3: The response surface showing the effects of $\mathrm{NaCl}$, exogenous melatonin treatment and germination time on DPPH radical scavenging activity and total antioxidant activity in mung bean sprouts. 


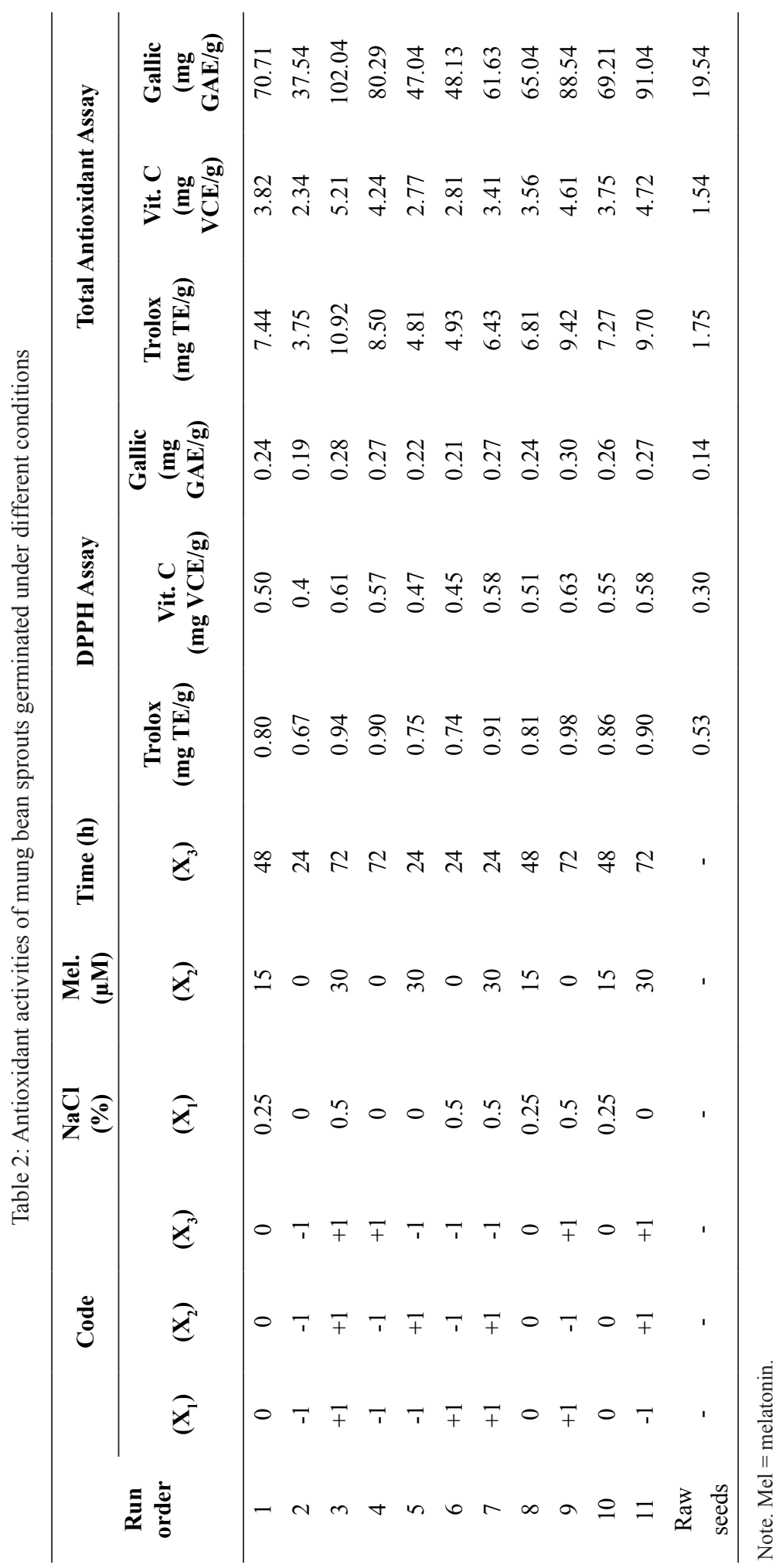

Journal of Sustainability Science and Management Volume 16 Number 2, February 2021: 79-93 
Table 3: ANOVA of regression for endogenous melatonin, total phenolic content and antioxidant activities of germinated mung bean sprouts

\begin{tabular}{cccc}
\hline Equation (coded factors) & $\mathbf{R}^{2}$ & Lack of fit & Significant model \\
\hline $\mathrm{Y}_{1}=326.64+94.56 \mathrm{X}_{1}+311.71 \mathrm{X}_{2}+63.39 \mathrm{X}_{3}$ & 0.9971 & $\mathrm{NS}$ & $\begin{array}{l}\mathrm{X}_{1}^{* * *}, \mathrm{X}_{2}^{* * *}, \mathrm{X}_{3}^{* *}, \\
+88.34 \mathrm{X}_{1} \mathrm{X}_{2}+17.10 \mathrm{X}_{1} \mathrm{X}_{3}+57.18 \mathrm{X}_{2} \mathrm{X}_{3}\end{array}$ \\
$\mathrm{Y}_{2}=1.24+0.11 \mathrm{X}_{1}+0.087 \mathrm{X}_{3}+0.46 \mathrm{X}_{3}$ & 0.9829 & $\mathrm{NS}$ & $\mathrm{X}_{1}^{* *}, \mathrm{X}_{2}^{* *}, \mathrm{X}_{3}^{* * *}$ \\
$\mathrm{Y}_{3}=0.84+0.043 \mathrm{X}_{1}+0.029 \mathrm{X}_{2}+0.081 \mathrm{X}_{3}$ & 0.8101 & $\mathrm{NS}$ & $\mathrm{X}_{1}^{*}, \mathrm{X}_{3}^{* * *}$ \\
$\mathrm{Y}_{4}=0.53+0.032 \mathrm{X}_{1}+0.021 \mathrm{X}_{2}+0.061 \mathrm{X}_{3}$ & 0.8101 & $\mathrm{NS}$ & $\mathrm{X}_{1}^{*}, \mathrm{X}_{3}^{* *}$ \\
$\mathrm{Y}_{5}=0.25+0.015 \mathrm{X}_{1}+0.009896 \mathrm{X}_{2}+0.028 \mathrm{X}_{3}$ & 0.8101 & $\mathrm{NS}$ & $\mathrm{X}_{1}^{*}, \mathrm{X}_{3}^{* *}$ \\
$\mathrm{Y}_{6}=7.27+0.62 \mathrm{X}_{1}+0.66 \mathrm{X}_{2}+2.33 \mathrm{X}_{3}$ & 0.9924 & $\mathrm{NS}$ & $\mathrm{X}_{1}^{* * *}, \mathrm{X}_{2}^{* * *}, \mathrm{X}_{3}^{* * *}$ \\
$\mathrm{Y}_{7}=3.75+0.25 \mathrm{X}_{1}+0.26 \mathrm{X}_{2}+0.93 \mathrm{X}_{3}$ & 0.9924 & $\mathrm{NS}$ & $\mathrm{X}_{1}^{* * *}, \mathrm{X}_{2}^{* * *}, \mathrm{X}_{3}^{* * *}$ \\
$\mathrm{Y}_{8}=69.20+5.55 \mathrm{X}_{1}+5.91 \mathrm{X}_{2}+20.95 \mathrm{X}_{3}$ & 0.9924 & $\mathrm{NS}$ & $\mathrm{X}_{1}^{* * *}, \mathrm{X}_{2}^{* * *}, \mathrm{X}_{3}^{* * *}$ \\
\hline
\end{tabular}

Y1; melatonin, Y2; total phenolic content, Y3; DPPH-Trolox equivalent, Y4; DPPH-Vit. C equivalent, Y5; DPPH-Gallic equivalent, Y6; total antioxidant-Trolox equivalent, Y7; total antioxidant -Vit. $\mathrm{C}$ equivalent, $\mathrm{Y} 8$; total antioxidant -Gallic equivalent, $\mathrm{X} 1 ; \mathrm{NaCl}$ concentration, $\mathrm{X} 2$; exogenous concentration, $\mathrm{X} 3$; germination time, ${ }^{*}$ Significant at $\mathrm{p} \leq 0.05,{ }^{*}$ Significant at $\mathrm{p} \leq 0.01,{ }^{* * * \text { Significant at }}$ $\mathrm{p} \leq 0.001$, NS; Not significant.

\section{Optimization of Mung Bean Seed Germination}

The results of ANOVA for the responses with corresponding coefficients of multiple determination $\left(\mathrm{R}^{2}\right)$ and lack of fit for germinated mung bean seeds are shown in Table 3. Analysis of variance (ANOVA) showed that the regression models for melatonin, total phenolic content and antioxidant activities were statistically significant $(p<0.001)$, with $\mathrm{R}^{2}$ more than 0.81 , indicating good adjustment of the models to the experimental data. The lack of fit for all parameters was insignificant, indicating that the models also fitted well. To simultaneously maximize the values of endogenous melatonin, TPC content, DPPH radical scavenging and total antioxidant capacities, the optimization process was performed using the Design-Expert software. The results indicated that the optimal solution for combination of variables was germination of mung bean seeds under $0.5 \% \mathrm{NaCl}$ with 30 $\mu \mathrm{M}$ of exogenous melatonin solution for $72 \mathrm{~h}$. The predicted values for the optimal conditions were $958.92 \mathrm{ng} / \mathrm{g}$ for melatonin, $1.90 \mathrm{mg} / \mathrm{g}$ for TPC, $0.99 \mathrm{mg} \mathrm{TE} / \mathrm{g}, 0.65 \mathrm{mg} \mathrm{VCE} / \mathrm{g}, 0.30 \mathrm{mg}$ GAE/g for DPPH radical scavenging assay and $10.86 \mathrm{mg} \mathrm{TE} / \mathrm{g}, 5.19 \mathrm{mg} \mathrm{VCE} / \mathrm{g}$ and 101.61 $\mathrm{mg}$ GAE/g for total antioxidant capacity by the phosphomolybdate assay (Table 4). The reliability of the optimum conditions obtained was also verified. The results of the experimental values were compared with the predicted values as presented in Table 4 . The results revealed that the experimental values obtained from the germination of mung bean seeds under optimum conditions were comparable to the predicted values. These results suggested that the predictive models generated were validated, and the optimization process of the conditions was satisfactory.

Germination of mung bean seeds under optimal salinity stress increased the levels of bioactive compounds and antioxidants in the sprouts. Enrichment of melatonin during sprouting improved the levels of endogenous melatonin and total phenolic compounds, and it 
Table 4: Comparison of predicted and experimental values of the response tested at optimum conditions

\begin{tabular}{lccc}
\hline \multicolumn{1}{c}{ Responses } & $\begin{array}{c}\text { Predicted } \\
\text { values }\end{array}$ & $\begin{array}{c}\text { Experimental values } \\
\text { at } \mathbf{0 . 5 \%} \mathbf{~ N a C l , ~ 3 0 ~} \boldsymbol{\mu M} \text { Mel, 72 h }\end{array}$ & $\begin{array}{c}\text { Mean } \\
\text { difference }\end{array}$ \\
\hline Melatonin (ng/g) & 958.92 & $942.88 \pm 48.56$ & -15.12 \\
TPC (mg/g) & 1.90 & $1.83 \pm 0.04$ & -0.07 \\
DPPH - TE (mg TE/g) & 0.99 & $0.95 \pm 0.01$ & -0.04 \\
DPPH - VC (mg VCE/g) & 0.65 & $0.62 \pm 0.01$ & -0.03 \\
DPPH - GAE (mg GAE/g) & 0.30 & $0.29 \pm 0.01$ & -0.01 \\
TAC - TE (mg TE/g) & 10.86 & $11.02 \pm 0.51$ & 0.16 \\
TAC - VC (mg VCE/g) & 5.19 & $5.25 \pm 0.27$ & 0.06 \\
TAC - GAE (mg GAE/g) & 101.61 & $102.96 \pm 4.705$ & 1.35 \\
Germination percentage (\%) & 92.00 & $92.50 \pm 3.54$ & 0.50 \\
\hline
\end{tabular}

also increased the quality of sprout production (Aguilera et al., 2015). The high germination rate of seeds (over 92\%) suggested that the optimal conditions could be considered as an alternative strategy to produce mung bean sprouts with high concentrations of melatonin and total phenolic compounds.

\section{Conclusion}

Endogenous melatonin content, total phenolic compounds and antioxidant capacity of mung bean sprouts were enhanced by optimizing germination conditions, including the germination time, $\mathrm{NaCl}$ level and exogenous melatonin concentration, using fractional factorial design with the response surface methodology. The optimal condition is considered an effective process that could be adopted to increase melatonin and phenolic in the production of ready-to-eat mung bean sprouts. High melatonin and total phenolic compounds in mung bean sprouts show potential as a functional ingredient for the food industry.

\section{Acknowledgements}

This research was financially supported by Mahasarakham University (fiscal year 2018).

\section{References}

Aguilera-Gutiérrez, Y., Herrera, T., Benitez, V., Esteban, R. M., \& Martín-Cabrejas, M. A. (2015). Estimation of scavenging capacity of melatonin and other antioxidants: Contribution and evaluation in germinated seeds.

Aguilera, Y., Herrera, T., Liébana, R., RebolloHernanz, M., Sanchez-Puelles, C., \& Martín-Cabrejas, M. A. (2015). Impact of melatonin enrichment during germination of legumes on bioactive compounds and antioxidant activity. Journal of Agricultural and Food Chemistry, 63(36), 7967-7974.

AOAC (Association of Official Analytical Chemists). 2000. Official Methods of Analysis. $17^{\text {th }}$ ed. Washington D.C.

Arendt, J. (1995). Light-dark control of melatonin synthesis. Melatonin and the pineal gland. Chapman and Hall London. pp 201-285.

Arendt, J., \& Deacon, S. (1997). Treatment of circadian rhythm disorders melatonin. Chronobiology International, 14(2), 185-204.

Arnao, M. B., \& Hernández-Ruiz, J. (2006). The physiological function of melatonin in plants. Plant Signaling \& Behavior, 1(3), 89-95. 
Arnao, M. B., \& Hernández-Ruiz, J. (2013). Growth conditions determine different melatonin levels in Lupinus albus L. Journal of Pineal Research, 55(2), 149-155.

Cáceres, P. J., Martínez-Villaluenga, C., Amigo, L., \& Frias, J. (2014). Maximising the phytochemical content and antioxidant activity of Ecuadorian brown rice sprouts through optimal germination conditions. Food Chemistry, 152, 407-414.

Cardinali, D. P., Brusco, L. I., Pérez, L. S., \& Furio, A. M. (2002). Melatonin in sleep disorders and jet-lag. Neuro endocrinology letters, 23(3), 9-13.

Carrillo-Vico, A., Guerrero, J. M., Lardone, P. J., \& Reiter, R. J. (2005). A review of the multiple actions of melatonin on the immune system. Endocrine, 27(2), 189200.

Chowdhury, F. T., Halim, M. A., Hossain, F., \& Akhtar, N. (2018). Effects of sodium chloride on germination and seedling growth of Sunflower (Helianthus annuus L.). Jahangirnagar University Journal of Biological Sciences, 7(1), 35-44.

Dahiya, P.K.; Linnemann, A.R.; van Boekel, M.A.J.S.; Khetarpaul, N.; Grewal, R.B.; Nout, M.J.R. (2013). Mung bean: Technological and nutritional potential. Critical Reviews in Food Science and Nutrition, 55(5), 670-688.

Doblado, R.; Frías, J.; Vidal-Valverde, C. (2007). Changes in vitamin $C$ content and antioxidant capacity of raw and germinated cowpea (Vigna sinensis var. carilla) seeds induced by high pressure treatment. Food Chemistry, 101(3), 918-923.

Gan, R. Y., Wang, M. F., Lui, W. Y., Wu, K., \& Corke, H. (2016). Dynamic changes in phytochemical composition and antioxidant capacity in green and black mung bean (Vigna radiata) sprouts. International Journal of Food Science \& Technology, 51(9), 20902098.
Gengmao, Z., Yu, H., Xing, S., Shihui, L., Quanmei, S., \& Changhai, W.(2015). Salinity stress increases secondary metabolites and enzyme activity in safflower. Industrial Crops and Products, 64, 175-181.

Guerrero, J. M., \& Reiter, R. J. (2002). Melatoninimmune system relationships. Current topics in medicinal chemistry, 2(2), 167179.

Guo, X., Li, T., Tang, K., \& Liu, R. H. (2012). Effect of germination on phytochemical profiles and antioxidant activity of mung bean sprouts (Vigna radiata). Journal of Agricultural and Food Chemistry, 60(44), 11050-11055.

Huang, X., Cai, W., \& Xu, B. (2014). Kinetic changes of nutrients and antioxidant capacities of germinated soybean (Glycine max L.) and mung bean (Vigna radiata L.) with germination time. Food Chemistry, 143, 268-276.

Iqbal, S., Bhanger, M. I., \& Anwar, F. (2005). Antioxidant properties and components of some commercially available varieties of rice bran in Pakistan. Food Chemistry, 93(2), 265-272.

Khan, M. I. R., Asgher, M., \& Khan, N. A. (2014). Alleviation of salt-induced photosynthesis and growth inhibition by salicylic acid involves glycinebetaine and ethylene in mung bean (Vigna radiata L.). Plant Physiology and Biochemistry, 80, 67-74.

Kocadağl1, T., Yılmaz, C., \& Gökmen, V. (2014). Determination of melatonin and its isomer in foods by liquid chromatography tandem mass spectrometry. Food Chemistry, 153, 151-156.

Lim, J. H., Park, K. J., Kim, B. K., Jeong, J. W., \& Kim, H. J. (2012). Effect of salinity stress on phenolic compounds and carotenoids in buckwheat (Fagopyrum esculentum M.) sprout. Food Chemistry, 135(3), 10651070. 
Liu, N., Jin, Z., Wang, S., Gong, B., Wen, D., Wang, X., ...\& Shi, Q. (2015). Sodic alkaline stress mitigation with exogenous melatonin involves reactive oxygen metabolism and ion homeostasis in tomato. Scientia Horticulturae, 181, 18-25.

Maestroni, G. J. (2001). The immunotherapeutic potential of melatonin. Expert opinion on investigational drugs, 10(3), 467-476.

Martín-Cabrejas, M. A., Aguilera, Y., Benitez, V., \& Reiter, R. J. (2017). Melatonin synthesis in fermented foods. In Fermented foods in health and disease prevention (pp. 105-129). Academic Press.

Mendoza-Sánchez, M., Guevara-González, R. G., Castaño-Tostado, E., Mercado-Silva, E. M., Acosta-Gallegos, J. A., Rocha-Guzmán, N. E., \& Reynoso-Camacho, R. (2016). Effect of chemical stress on germination of cv Dalia bean (Phaseolus vularis L.) as an alternative to increase antioxidant and nutraceutical compounds in sprouts. Food Chemistry, 212, 128-137.

Mukherjee, S., David, A., Yadav, S., Baluška, F., \& Bhatla, S. C. (2014). Salt stress-induced seedling growth inhibition coincides with differential distribution of serotonin and melatonin in sunflower seedling roots and cotyledons. Physiologia plantarum, 152(4), 714-728.

Murch, S. J., KrishnaRaj, S., \& Saxena, P. K. (2000). Tryptophan is a precursor for melatonin and serotonin biosynthesis in in vitro regenerated St. John's wort (Hypericum perforatum L. cv. Anthos) plants. Plant Cell Reports, 19(7), 698-704.

Pandi-Perumal, S.R., Srinivassan, V., Maestroni, G.J.M., Cardinali, D.P., Poeggeler, B., Harderland, R. (2006) Melatonin. Nature.s most versatile biological signal? The FEBS Journal, 273: 2813-2836.

Phatak, R. S., \& Hendre, A. S. (2014). Total antioxidant capacity (TAC) of fresh leaves of Kalanchoe pinnata. Journal of Pharmacognosy and Phytochemistry, 2(5).
Piechota, A., Lipinska, S., Szemraj, J., \& Goraca, A. (2010). Long-term melatonin administration enhances the antioxidant potential of human plasma maintained after discontinuation of the treatment. General physiology and biophysics, 29(2), 144-150.

Pothinuch, P., \& Tongchitpakdee, S. (2011). Melatonin contents in mulberry (Morus spp.) leaves: effects of sample preparation, cultivar, leaf age and tea processing. Food Chemistry, 128(2), 415-419.

Reiter, R. J., Manchester, L. C., \& Tan, D. X. (2005). Melatonin in walnuts: influence on levels of melatonin and total antioxidant capacity of blood. Nutrition, 21(9), 920924.

Sae-Teaw, M., Johns, J., Johns, N. P., \& Subongkot, S. (2013). Serum melatonin levels and antioxidant capacities after consumption of pineapple, orange, or banana by healthy male volunteers. Journal of pineal research, 55(1), 58-64.

Saha, P., Kunda, P., \& Biswas, A. K. (2012). Influence of sodium chloride on the regulation of Krebs cycle intermediates and enzymes of respiratory chain in mung bean (Vigna radiata L. Wilczek) seedlings. Plant Physiology and Biochemistry, 60, 214-222.

Saleh, H. M., Hassan, A. A., Mansour, E. H., Fahmy, H. A., \& El-Bedawey, A. E. F. A. (2019). Melatonin, phenolics content and antioxidant activity of germinated selected legumes and their fractions. Journal of the Saudi Society of Agricultural Sciences, 18(3), 294-301.

Sangsopha, J., Pratheepawanit Johns, N., Johns J., \& Moongngarm, A. (2020). Dietary sources of melatonin and benefits from production of high melatonin pasteurized milk. Journal of Food Science and Technology, 57(2), 2026-2037.

Sehrawat, N., Yadav, M., Bhat, K. V., Sairam, R. K., \& Jaiwal, P. K. (2014). Evaluation of mung bean genotypes for salt tolerance at early seedling growth stage. Biocatalysis 
and Agricultural Biotechnology, 3(4), 108113.

Shimada, K., Fujikawa, K., Yahara, K., \& Nakamura, T. (1992). Antioxidative properties of xanthan on the autoxidation of soybean oil in cyclodextrin emulsion. Journal of Agricultural and Food Chemistry, 40(6), 945-948.

Srinivasan, V., Pandi-Perumal, S. R., Maestroni, G. J. M., Esquifino, A. I., Hardeland, R., \& Cardinali, D. P. (2005). Role of melatonin in neurodegenerative diseases. Neurotoxicity Research, 7(4), 293-318.

Tan, D. X., Hardeland, R., Manchester, L. C., Korkmaz, A., Ma, S., Rosales-Corral, S., \& Reiter, R. J. (2012). Functional roles of melatonin in plants, and perspectives in nutritional and agricultural science. Journal of Experimental Botany, 63(2), 577-597.

Tan, D. X., Hardeland, R., Manchester, L. C., Poeggeler, B., Lopez-Burillo, S., Mayo, J. C., \& Reiter, R. J. (2003). Mechanistic and comparative studies of melatonin and classic antioxidants in terms of their interactions with the ABTS cation radical. Journal of pineal research, 34(4), 249-259.
Tang, D., Dong, Y., Guo, N., Li, L., \& Ren, H. (2014). Metabolomic analysis of the polyphenols in germinating mung beans (Vigna radiata) seeds and sprouts. Journal of the Science of Food and Agriculture, 94(8), 16391647.

Win, K. T., \& Oo, A. Z. (2015). Genotypic difference in salinity tolerance during early vegetative growth of cowpea (Vigna unguiculata L. Walp.) from Myanmar. Biocatalysis and Agricultural Biotechnology, 4(4), 449-455.

Wu, Y. H., \& Swaab, D. F. (2005). The human pineal gland and melatonin in aging and Alzheimer's disease. Journal of pineal research, 38(3), 145-152.

Zhang, N., Sun, Q., Zhang, H., Cao, Y., Weeda, S., Ren, S., \& Guo, Y. D. (2015). Roles of melatonin in abiotic stress resistance in plants. Journal of Experimental Botany, 66(3), 647-656.

Zhdanova, I. V. (2005). Melatonin as a hypnotic: Pro. Sleep Medicine Reviews, 9(1), 51-65. 